\title{
Notícia: Diretrizes Curriculares Nacionais Para os Cursos de Graduação em Psicologia ${ }^{1}$
}

\author{
Câmara de Educação Superior
}

Conselho Nacional de Educação

\section{News: National Curriculum Directives for Undergraduate Courses in Psychology}

\section{Conselho Nacional de Educação Câmara de Educação Superior Resolução nº 8, de 7 de maio de 2004.}

Institui as Diretrizes Curriculares para os cursos de graduação em Psicologia.

O Presidente da Câmara de Educação Superior do Conselho Nacional de Educação, tendo em vista o disposto no Art. $9^{\circ}$, do $\S 2^{\circ}$, alínea “c", da Lei 9.131, de 25 de novembro de 1995, e com fundamento nos Pareceres CNE/CES 1.314, de 7 de novembro de 2001, retificado pelo CNE/CES 72, de 19 de fevereiro de 2002, em adendo ao CNE/CES 62, de 19 de fevereiro de 2004, homologado pelo Senhor Ministro de Estado da Educação em 12 de abril de 2004, resolve:

Art. $1^{\circ}$ A presente Resolução institui as Diretrizes Curriculares Nacionais para os cursos de graduação em Psicologia, a serem observadas pelas Instituições de Ensino Superior do País.

Art. $2^{\circ}$ As Diretrizes Curriculares para os cursos de graduação em Psicologia constituem as orientações sobre princípios, fundamentos, condições de oferecimento e procedimentos para o planejamento, a implementação e a avaliação deste curso.

Art. $3^{\circ} \mathrm{O}$ curso de graduação em Psicologia tem como meta central a formação do Psicólogo voltado para a atuação profissional, para a pesquisa e para o ensino de Psicologia, e deve assegurar uma formação baseada nos seguintes princípios e compromissos:

a) Construção e desenvolvimento do conhecimento científico em Psicologia;

b) Compreensão dos múltiplos referenciais que buscam apreender a amplitude do fenômeno psicológico em suas interfaces com os fenômenos biológicos e sociais;

c) Reconhecimento da diversidade de perspectivas necessárias para compreensão do ser humano e incentivo à interlocução com campos de conhecimento que permitam a apreensão da complexidade e multideterminação do fenômeno psicológico;

1 Notícia encaminhada pela Profa. Maria Angela Guimarães Feitosa do Instituto de Psicologia da Universidade de Brasília. O documento refere-se à Resolução n ${ }^{\circ} 8$ de 2004, publicada no Diário Oficial da União em 18 de maio de 2004, Seção 1, p. 16 e 17. Pode ser consultado, juntamente com os pareceres CNE/CES n ${ }^{\circ} 1.314$, de 7 de novembro de 2001, CNE/CES $\mathrm{n}^{\circ} 72$, de 20 de fevereiro de 2002 e CNE/CES n ${ }^{\circ} 62$, de 19 de fevereiro de 2004 em http://www.mec.gov.br/cne/diretrizes.shtm. d) Compreensão crítica dos fenômenos sociais, econômicos, culturais e políticos do País, fundamentais ao exercício da cidadania e da profissão;

e) Atuação em diferentes contextos considerando as necessidades sociais, os direitos humanos, tendo em vista a promoção da qualidade de vida dos indivíduos, grupos, organizações e comunidades;

f) Respeito à ética nas relações com clientes e usuários, com colegas, com o público e na produção e divulgação de pesquisas, trabalhos e informações da área da Psicologia;

g) Aprimoramento e capacitação contínuos.

Art. $4^{\circ}$ A formação em Psicologia tem por objetivos gerais dotar o profissional dos conhecimentos requeridos para o exercício das seguintes competências e habilidades gerais:

a) Atenção à saúde: os profissionais devem estar aptos a desenvolver ações de prevenção, promoção, proteção e reabilitação da saúde psicológica e psicossocial, tanto em nível individual quanto coletivo, bem como a realizar seus serviços dentro dos mais altos padrões de qualidade e dos princípios da ética/bioética;

b) Tomada de decisões: o trabalho dos profissionais deve estar fundamentado na capacidade de avaliar, sistematizar e decidir as condutas mais adequadas, baseadas em evidências científicas;

c) Comunicação: os profissionais devem ser acessíveis e devem manter os princípios éticos no uso das informações a eles confiadas, na interação com outros profissionais de saúde e o público em geral;

d) Liderança: no trabalho em equipe multiprofissional, os profissionais deverão estar aptos a assumirem posições de liderança, sempre tendo em vista o bem estar da comunidade;

e) Administração e gerenciamento: os profissionais devem estar aptos a tomar iniciativas, fazer o gerenciamento e administração da força de trabalho, dos recursos físicos e materiais e de informação, da mesma forma que devem estar aptos a serem empreendedores, gestores, empregadores ou líderes nas equipes de trabalho;

f) Educação permanente: os profissionais devem ser capazes de aprender continuamente, tanto na sua formação, quanto na sua prática, e de ter responsabilidade e compromisso com a sua educação e o treinamento das futuras gerações de profissionais, estimulando e desenvolvendo a mobilidade acadêmica e profissional, a formação e a cooperação através de redes nacionais e internacionais. 
Art. $5^{\circ}$ A formação em Psicologia exige que a proposta do curso articule os conhecimentos, habilidades e competências em torno dos seguintes eixos estruturantes:

a) Fundamentos epistemológicos e históricos que permitam ao formando o conhecimento das bases epistemológicas presentes na construção do saber psicológico, desenvolvendo a capacidade para avaliar criticamente as linhas de pensamento em Psicologia;

b) Fundamentos teórico-metodológicos que garantam a apropriação crítica do conhecimento disponível, assegurando uma visão abrangente dos diferentes métodos e estratégias de produção do conhecimento científico em Psicologia;

c) Procedimentos para a investigação científica e a prática profissional, de forma a garantir tanto o domínio de instrumentos e estratégias de avaliação e de intervenção, quanto a competência para selecioná-los, avaliá-los e adequá-los a problemas e contextos específicos de investigação e ação profissional;

d) Fenômenos e processos psicológicos, que constituem classicamente objeto de investigação e atuação no domínio da Psicologia, de forma a propiciar amplo conhecimento de suas características, questões conceituais e modelos explicativos construídos no campo, assim como seu desenvolvimento recente;

e) Interfaces com campos afins do conhecimento para demarcar a natureza e a especificidade do fenômeno psicológico e percebê-lo em sua interação com fenômenos biológicos, humanos e sociais, assegurando uma compreensão integral e contextualizada dos fenômenos e processos psicológicos;

f) Práticas profissionais voltadas para assegurar um núcleo básico de competências que permitam a atuação profissional e a inserção do graduado em diferentes contextos institucionais e sociais, de forma articulada com profissionais de áreas afins.

Art. $6^{\circ} \mathrm{A}$ identidade do curso de Psicologia no país é conferida através de um núcleo comum de formação, definido por um conjunto de competências, habilidades e conhecimentos.

Art. $7^{\circ} \mathrm{O}$ núcleo comum da formação em Psicologia estabelece uma base homogênea para a formação no País e uma capacitação básica para lidar com os conteúdos da Psicologia, enquanto campo de conhecimento e de atuação.

Art. $8^{\circ}$ As competências reportam-se a desempenhos e atuações requeridas do formado em Psicologia, e devem garantir ao profissional um domínio básico de conhecimentos psicológicos e a capacidade de utilizá-los em diferentes contextos que demandam a investigação, análise, avaliação, prevenção e atuação em processos psicológicos e psicossociais, e na promoção da qualidade de vida. São elas:

a) Analisar o campo de atuação profissional e seus desafios contemporâneos;

b) Analisar o contexto em que atua profissionalmente em suas dimensões institucional e organizacional, explicitando a dinâmica das interações entre os seus agentes sociais;

c) Identificar e analisar necessidades de natureza psicológica, diagnosticar, elaborar projetos, planejar e agir de forma coerente com referenciais teóricos e características da população-alvo; d) Identificar, definir e formular questões de investigação científica no campo da Psicologia, vinculando-as a decisões metodológicas quanto à escolha, coleta, e análise de dados em projetos de pesquisa;

e) Escolher e utilizar instrumentos e procedimentos de coleta de dados em Psicologia, tendo em vista a sua pertinência;

f) Avaliar fenômenos humanos de ordem cognitiva, comportamental e afetiva, em diferentes contextos;

g) Realizar diagnóstico e avaliação de processos psicológicos de indivíduos, de grupos e de organizações;

h) Coordenar e manejar processos grupais, considerando as diferenças individuais e sócio-culturais dos seus membros;

i) Atuar inter e multiprofissionalmente, sempre que a compreensão dos processos e fenômenos envolvidos assim o recomendar;

j) Relacionar-se com o outro de modo a propiciar o desenvolvimento de vínculos interpessoais requeridos na sua atuação profissional;

k) Atuar profissionalmente, em diferentes níveis de ação, de caráter preventivo ou terapêutico, considerando as características das situações e dos problemas específicos com os quais se depara;

1) Realizar orientação, aconselhamento psicológico e psicoterapia;

m) Elaborar relatos científicos, pareceres técnicos, laudos e outras comunicações profissionais, inclusive materiais de divulgação;

n) Apresentar trabalhos e discutir idéias em público;

o) Saber buscar e usar o conhecimento científico necessário à atuação profissional, assim como gerar conhecimento a partir da prática profissional.

Art. $9^{\circ}$ As competências, básicas, devem se apoiar nas habilidades de:

a) Levantar informação bibliográfica em indexadores, periódicos, livros, manuais técnicos e outras fontes especializadas através de meios convencionais e eletrônicos;

b) Ler e interpretar comunicações científicas e relatórios na área da Psicologia;

c) Utilizar o método experimental, de observação e outros métodos de investigação científica;

d) Planejar e realizar várias formas de entrevistas com diferentes finalidades e em diferentes contextos;

e) Analisar, descrever e interpretar relações entre contextos e processos psicológicos e comportamentais;

f) Descrever, analisar e interpretar manifestações verbais e não verbais como fontes primárias de acesso a estados subjetivos;

g) Utilizar os recursos da matemática, da estatística e da informática para a análise e apresentação de dados e para a preparação das atividades profissionais em Psicologia.

Art. 10. Pela diversidade de orientações teórico-metodológicas, práticas e contextos de inserção profissional, a formação em Psicologia diferencia-se em ênfases curriculares, entendidas como um conjunto delimitado e articulado de competências e habilidades que configuram oportunidades de concentração de estudos e estágios em algum domínio da Psicologia. 
Art. 11. A organização do curso de Psicologia deve explicitar e detalhar as ênfases curriculares que adotará, descrevendo-as detalhadamente em sua concepção e estrutura.

$\S 1^{\circ}$ A definição das ênfases curriculares, no projeto do curso, envolverá um subconjunto de competências e habilidades dentre aquelas que integram o domínio das competências gerais do psicólogo, compatível com demandas sociais atuais e ou potenciais, e com a vocação e condições da instituição.

$\S 2^{\circ}$ A partir das competências e habilidades definidas, o projeto de curso deverá especificar conteúdos e experiências de ensino capazes de garantir a concentração no domínio abarcado pelas ênfases propostas.

$\S 3^{\circ} \mathrm{A}$ instituição deverá oferecer, pelo menos, duas ênfases curriculares que assegurem possibilidade de escolha por parte do aluno.

$\S 4^{\circ} \mathrm{O}$ projeto de curso deve prever mecanismos que permitam ao aluno escolher uma ou mais dentre as ênfases propostas.

Art. 12. Os domínios mais consolidados de atuação profissional do psicólogo no país podem constituir ponto de partida para a definição de ênfases curriculares, sem prejuízo para que no projeto de curso as instituições formadoras concebam recortes inovadores de competências que venham a instituir novos arranjos de práticas no campo.

$\S 1^{\circ} \mathrm{O}$ subconjunto de competências definido como escopo de cada ênfase deverá ser suficientemente abrangente para não configurar uma especialização em uma prática, procedimento ou local de atuação do psicólogo. São possibilidades de ênfases, entre outras, para o curso de Psicologia:

a) Psicologia e processos de investigação científica que consiste na concentração em conhecimentos, habilidades e competências de pesquisa já definidas no núcleo comum da formação, capacitando o formando para analisar criticamente diferentes estratégias de pesquisa, conceber, conduzir e relatar investigações científicas de distintas naturezas;

b) Psicologia e processos educativos que compreende a concentração nas competências para diagnosticar necessidades, planejar condições e realizar procedimentos que envolvam o processo de educação e de ensino-apredizagem através do desenvolvimento de conhecimentos, habilidades, atitudes e valores de indivíduos e grupos em distintos contextos institucionais em que tais necessidades sejam detectadas;

c) Psicologia e processos de gestão que abarca a concentração em competências definidas no núcleo comum da formação para o diagnóstico, planejamento e uso de procedimentos e técnicas específicas voltadas para analisar criticamente e aprimorar os processos de gestão organizacional, em distintas organizações e instituições;

d) Psicologia e processos de prevenção e promoção da saúde que consiste na concentração em competências que garantam ações de caráter preventivo, em nível individual e coletivo, voltadas a capacitação de indivíduos, grupos, instituições e comunidades para protegerem e promoverem a saúde e qualidade de vida, em diferentes contextos em que tais ações possam ser demandadas;

e) Psicologia e processos clínicos que envolve a concentração em competências para atuar, de forma ética e coe- rente com referenciais teóricos, valendo-se de processos psicodiagnósticos, de aconselhamento, psicoterapia e outras estratégias clínicas, frente a questões e demandas de ordem psicológica apresentadas por indivíduos ou grupos em distintos contextos;

f) Psicologia e processos de avaliação diagnóstica que implica na concentração em competências referentes ao uso e ao desenvolvimento de diferentes recursos, estratégias e instrumentos de observação e avaliação úteis para a compreensão diagnóstica em diversos domínios e níveis de ação profissional.

$\S 2^{\circ}$ As definições gerais das ênfases propostas no projeto de curso devem ser acompanhadas pelo detalhamento das competências e pelo conjunto de disciplinas que darão o suporte do conhecimento acumulado necessário para o seu desenvolvimento pelo formando.

$\S 3^{\circ}$ As ênfases devem incorporar estágio supervisionado estruturado para garantir o desenvolvimento das competências específicas previstas.

Art. 13. A formação do professor de Psicologia dar-se-á em um projeto pedagógico complementar e diferenciado, elaborado em conformidade com a legislação que regulamenta a formação de professores no país.

$\S 1^{\circ} \mathrm{O}$ projeto pedagógico para a formação do Professor de Psicologia deve propiciar o desenvolvimento das competências e habilidades básicas constantes no núcleo comum do curso de Psicologia e daquelas previstas nas Diretrizes Nacionais para a formação do professor da Educação Básica, em nível superior.

Art. 14. A organização do curso de Psicologia deve, de forma articulada, garantir o desenvolvimento das competências do núcleo comum, seguido das competências das partes diversificadas - ênfases - sem concebê-los, entretanto, como momentos estanques do processo de formação.

Art. 15. O projeto do curso deve explicitar todas as condições para o seu funcionamento, a carga horária efetiva global, do núcleo comum e das partes diversificadas, inclusive dos diferentes estágios supervisionados, bem como a duração máxima do curso.

Art. 16. O projeto do curso deverá prever, outrossim, procedimentos de auto-avaliação periódica, dos quais deverão resultar informações necessárias para o aprimoramento do curso.

Art. 17. As atividades acadêmicas devem fornecer elementos para a aquisição das competências, habilidades e conhecimentos básicos necessários ao exercício profissional. Assim, essas atividades devem, de forma sistemática e gradual, aproximar o formando do exercício profissional correspondente às competências previstas para a formação.

Art. 18. Os eixos estruturantes do curso deverão ser decompostos em conteúdos curriculares e agrupados em atividades acadêmicas, com objetivos de ensino, programas e procedimentos específicos de avaliação.

Art. 19. O planejamento acadêmico deve assegurar, em termos de carga horária e de planos de estudos, o envolvimento do aluno em atividades, individuais e de equipe, que incluam, entre outros:

a) Aulas, conferências e palestras;

b) Exercícios em laboratórios de Psicologia; 
c) Observação e descrição do comportamento em diferentes contextos;

d) Projetos de pesquisa desenvolvidos por docentes do curso;

e) Práticas didáticas na forma de monitorias, demonstrações e exercícios, como parte de disciplinas ou integradas a outras atividades acadêmicas;

f) Consultas supervisionadas em bibliotecas para identificação crítica de fontes relevantes;

g) Aplicação e avaliação de estratégias, técnicas, recursos e instrumentos psicológicos;

h) Visitas documentadas através de relatórios a instituições e locais onde estejam sendo desenvolvidos trabalhos com a participação de profissionais de Psicologia;

i) Projetos de extensão universitária e eventos de divulgação do conhecimento, passíveis de avaliação e aprovados pela instituição;

j) Práticas integrativas voltadas para o desenvolvimento de habilidades e competências em situações de complexidade variada, representativas do efetivo exercício profissional, sob a forma de estágio supervisionado.

Art. 20. Os estágios supervisionados são conjuntos de atividades de formação, programados e diretamente supervisionados por membros do corpo docente da instituição formadora e procuram assegurar a consolidação e articulação das competências estabelecidas.

Art. 21. Os estágios supervisionados visam assegurar o contato do formando com situações, contextos e instituições, permitindo que conhecimentos, habilidades e atitudes se concretizem em ações profissionais, sendo recomendável que as atividades do estágio supervisionado se distribuam ao longo do curso.
Art. 22. Os estágios supervisionados devem se estruturar em dois níveis - básico e específico - cada um com sua carga horária própria.

$\S 1^{\circ} \mathrm{O}$ estágio supervisionado básico incluirá o desenvolvimento de práticas integrativas das competências e habilidades previstas no núcleo comum.

$\S 2^{\circ}$ Cada estágio supervisionado específico incluirá o desenvolvimento de práticas integrativas das competências, habilidades e conhecimentos que definem cada ênfase proposta pelo projeto de curso.

$\S 3^{\circ}$ Os estágios básico e específico deverão perfazer, ao todo, pelo menos $15 \%$ da carga horária total do curso.

Art. 23. As atividades de estágio supervisionado devem ser documentadas de modo a permitir a avaliação, segundo parâmetros da instituição, do desenvolvimento das competências e habilidades previstas.

Art. 24. A instituição poderá reconhecer atividades realizadas pelo aluno em outras instituições, desde que estas contribuam para o desenvolvimento das habilidades e competências previstas no projeto de curso.

Art. 25. O projeto de curso deve prever a instalação de um Serviço de Psicologia com as funções de responder às exigências para a formação do psicólogo, congruente com as competências que o curso objetiva desenvolver no aluno e a demandas de serviço psicológico da comunidade na qual está inserido.

Art. 26. Esta Resolução entra em vigor na data de sua publicação, revogadas as disposições em contrário.

Conselheiro Edson de Oliveira Nunes Presidente da Câmara de Educação Superior

Recebido em 29.04.2004

Aceito em 22.08.2004 